\title{
ENFERMAGem PEDIATRICA E ABORdAgem dA fAMILIA: SUBSÍdIOS PARA o ENSINo de gRAduAção
}

\author{
Semiramis Melani Melo Rocha ${ }^{1}$ \\ Lucila Castanheira Nascimento ${ }^{2}$ \\ Regina Aparecida Garcia de Lima ${ }^{3}$
}

Rocha SMM, Nascimento LC, Lima RAG. Enfermagem pediátrica e abordagem da família: subsídios para o ensino de graduação. Rev Latino-am Enfermagem 2002 setembro-outubro; 10(5):709-14.

O objetivo deste artigo é apresentar instrumentos utilizados na abordagem de enfermagem da família, divulgados na literatura internacional, e fornecer subsídios para sua utilização, pela enfermagem brasileira, na assistência à crianças, em abordagens de saúde da família. As autoras apresentam a experiência de introduzir, no ensino de Enfermagem Pediátrica, uma metodologia de assistência sistematizada cujos instrumentos para levantamento de dados são o APGAR da família, geneograma e ecomapa. Argumentam que esses instrumentos não substituem a fundamentação teórica da assistência nem tão pouco a razão e o discernimento para dar sentido e significado aos dados e encontrar as melhores soluções para o cuidado à criança e sua família.

DESCRITORES: família, enfermagem pediátrica

\section{PEDIATRIC NURSING AND THE FAMILY APPROACH: SUBSIDIES FOR UNDERGRADUATE TEACHING}

This work aims at presenting the instruments used in the family nursing approach as depicted in the international literature as well as at providing subsidies for their utilization by Brazilian nursing professionals in family health approaches to child care. The authors present the experience of introducing a methodology for systematized care in Pediatric Nursing programs using instruments for data collection such as the family APGAR, Genogram and Ecomap. They argue that these instruments do not replace the theoretical basis of care or the reason and discernment in order to provide data with meaning and find better solutions to care for children and their family.

DESCRIPTORS: family, pediatric nursing

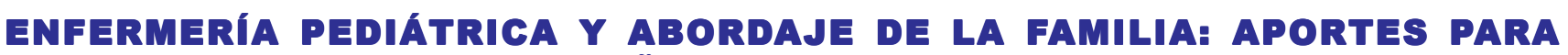 LA ENSEÑANZA de PRE-GRAdo}

El objetivo de este artículo es presentar instrumentos utilizados en el abordaje de enfermería de la familia, divulgados en la literatura internacional y ofrecer aportes para su utilización, por la enfermería brasileña, en la atención a niños, en abordajes de salud de la familia. Las autoras presentan la experiencia de introducir en la enseñanza de Enfermería Pediátrica, una metodología de atención sistematizada cuyos instrumentos para levantamiento de datos son el APGAR de la familia, genograma y ecomapa. Argumentan que estos instrumentos no van a substituir la fundamentación teórica de la atencion ni tan poco la razón y el discernimiento para dar sentido y significado a los datos y encontrar las mejores soluciones para el cuidado al niño y a su familia.

\section{DESCRIPTORES: familia, enfermería pediátrica}

${ }^{1}$ Enfermeira, Professor Titular, e-mail: smmrocha@eerp.usp.br; ${ }^{2}$ Enfermeira, Professor Assistente; ${ }^{3}$ Enfermeira, Professor Doutor. Escola de Enfermagem de Ribeirão Preto da Universidade de São Paulo, Centro Colaborador da OMS para o desenvolvimento da pesquisa em enfermagem 


\section{INTRODUÇÃO}

No século $X X$, as mudanças no perfil dos indicadores de morbimortalidade conseqüentes ao controle de doenças transmissíveis, emergência de doenças crônicas, distúrbios de comportamento, acidentes, assim como a transição demográfica foram amplamente apontados como determinantes das transformações nas práticas em saúde.

As ciências humanas tomaram a saúde como objeto de estudo, analisando as práticas, a qualidade do cuidado, as expectativas do cliente, a resolutividade e as profissões, buscando tornar os cidadãos mais conscientes de seu importante papel social. Incrementaram os estudos sobre os determinantes não biológicos do processo saúdedoença, relações familiares e bioética, reformulando conceitos de saúde, doença, papel do Estado e da sociedade.

$\mathrm{Na}$ tentativa de reorganizar a atenção básica em saúde, em substituição à prática assistencial vigente, voltada para a cura de doenças, o Ministério da Saúde do Brasil, em 1994, assumiu o desafio de incorporar, em seu plano de ações e metas prioritárias, as estratégias de Saúde da Família(1), embasadas nos princípios da universalidade, eqüidade e integralidade da assistência ${ }^{(2)}$.

Sob essa ótica, a estratégia utilizada no Programa Saúde da Família (PSF) visa à reversão do modelo assistencial atual. Tal estratégia elegeu como ponto básico o estabelecimento de vínculos e a criação de laços de compromisso e de co-responsabilidade entre os profissionais de saúde e a população. Para tanto, faz-se necessária a mudança do objeto de atenção, forma de atuação e organização dos serviços, em novas bases e critérios.

Para a orientação das práticas, o Programa Saúde da Família prevê: diagnóstico de saúde da comunidade, planejamento e programação local, complementariedade, abordagem multiprofissional, referência e contra-referência, educação continuada, integração intersetorial, acompanhamento, avaliação e controle social.

Nesse modelo, a família passa a ser objeto de atenção, compreendida a partir do ambiente onde vive, constroem-se as relações intra e extrafamiliares e desenvolve-se a luta pela melhoria das condições de vida. Somado a essa dimensão, é importante entender que as relações entre as famílias e os serviços de saúde estão inseridas em um conjunto de determinantes sociais, políticos e econômicos. Só a intervenção e recuperação do corpo biológico não tem respondido de forma plena às necessidades de saúde, pois estas vão além e demandam uma atenção que leve em conta a integralidade do ser humano, a qualidade de vida e a promoção da saúde.

$\mathrm{Na}$ atualidade, identificam-se várias concepções sobre saúde e família e várias abordagens que diferenciam medicina da família, enfermagem da família, programa de saúde da família e estratégias para a saúde da família.

A enfermagem da família tem sido abordada nas escolas de enfermagem desde o início de nossa profissão. A princípio, enfermeiras de saúde pública reconheceram a família como um importante fator no crescimento e desenvolvimento dos indivíduos, bem como na recuperação de doenças. Com o advento da teoria de sistemas, adaptada aos sistemas viventes por Bertalanffy, na década de 30, e introduzida na enfermagem, em 1960, o conceito de enfermagem da família tem sido entendido como cuidado de enfermagem prestado a todo sistema ou unidade familiar. Entretanto, é importante citar a existência, naquela época, de dificuldades por parte das estudantes de enfermagem em integrar o conceito de enfermagem da família em seus pensamentos conceituais ${ }^{(3)}$.

Atualmente, vários teóricos têm se empenhado em diferentes conceituações de família e enfermagem na assistência à família, focalizando o cuidado de acordo com o modelo utilizado. Assim, ora direcionam o cuidado do indivíduo no contexto da família, ora é a família com o indivíduo como contexto, e a tendência emergente é o cuidado da família como sistema, ou seja, a família é a unidade do cuidado.

Existem quatro maneiras pelas quais o conceito de família foi definido por enfermeiras: a família como ambiente, a família como um grupo de interação intersetorial, a família como uma unidade singular com limites definidos e como uma unidade em interação com o ambiente ${ }^{(4)}$.

Compreender essas diferentes configurações da enfermagem da família não prepara as enfermeiras para trabalhar com ela. É desejável que se aproximem das abordagens das ciências humanas e das teorias sobre terapias familiares. Essa necessidade desencadeou três tendências na enfermagem: um aumento de conteúdo nas disciplinas sobre família nos meios acadêmicos, aumento das pesquisas sobre família e a ampliação da prática clínica, tomando a família como objeto do cuidado.

As abordagens mencionadas são desenvolvidas 
para diferentes clientelas e adaptadas de acordo com diferenças socioculturais, organização dos sistemas de saúde, metas e objetivos a serem atingidos.

A experiência de ensino em Enfermagem Pediátrica levou-nos a constatar que, entre as áreas de conhecimento da enfermagem que se beneficiaram da abordagem de enfermagem da família, a assistência à criança é uma das que vem se destacando. Este fato pode ser evidenciado a partir da literatura de enfermagem, particularmente na assistência à criança com doença crônica, na assistência ao recém-nascido e ao adolescente e nos programas governamentais que enfatizam a importância do suporte da família para o acompanhamento do crescimento e desenvolvimento infantil ${ }^{(5-7)}$.

Considerando a necessidade de estratégias objetivas no processo de formação dos alunos de graduação em enfermagem, as autoras buscaram instrumentos na literatura de enfermagem para ampliar a metodologia de assistência até então centrada no modelo clínico para a abordagem de enfermagem da família.

Estes instrumentos não são específicos da Enfermagem Pediátrica e já vem sendo utilizados em outras áreas, mais especificamente em ambientes acadêmicos.

Experiências bem sucedidas no ensino de graduação levaram-nos a divulgar esses instrumentos para a comunidade de enfermeiros.

\section{OBJETIVOS}

- Apresentar instrumentos utilizados na abordagem de enfermagem da família, divulgados na literatura internacional de enfermagem.

- Fornecer subsídios para sua utilização no ensino de enfermagem, na assistência à criança.

\section{CONCEITOS E DEFINIÇÕES}

Família

Há várias definições de família (do latim famulus), e cada uma atende a uma finalidade. A Fundação Instituto Brasileiro de Geografia e Estatística - IBGE, a Secretaria da Receita Federal do Ministério da Fazenda, as instituições públicas e privadas de previdência social e seguro saúde adotam conceitos e definições adequados aos seus propósitos e objetivos. Algumas definições são importantes para serem utilizadas como indicadores econômicos, porém não são adequadas para a assistência de enfermagem. Conhecer a estrutura da família, sua composição, funções, papéis e como os membros se organizam e interagem entre si e com o ambiente é vital para o planejamento do cuidado. Além disso, deve-se adotar um conceito que permita englobar o maior número possível de variações encontradas na prática. Os pontos de partida para definição de família são os laços de consangüinidade, parentesco e acasalamento. Para a finalidade de construir instrumentos para abordagem de enfermagem da família destacamos duas definições que nos parecem mais apropriadas:

"Família, em um contexto amplo, são duas ou mais pessoas que vivem em uma mesma casa (usualmente), têm um vínculo emocional ou afetivo e desempenham tarefas sociais inter-relacionadas"(8). Embora ampla, essa definição não situa a criança em relação aos demais membros da família, portanto relacionamos a definição abaixo que contempla essa população.

"Famílias são relacionamentos em que pessoas vivem juntas, comprometidas, formam uma unidade econômica, cuidam dos mais jovens, identificam-se entre si e no grupo a que pertencem"(9).

A abordagem da enfermagem da família não desconsidera toda a sistematização já construída para a implantação do cuidado. Portanto, ela deve ser incorporada ao processo de enfermagem ${ }^{(8)}$ também conhecido como metodologia de assistência. Há várias adaptações do processo de enfermagem para assistência à criança, bem como modelos que tomam a família como unidade de cuidado. As etapas descritas sucintamente a seguir são utilizadas didaticamente para orientação dos alunos de graduação.

\section{Processo de enfermagem}

\section{- Histórico de enfermagem}

O histórico de enfermagem provê informações sobre a situação de saúde dos membros da família e o suporte emocional que pode ser esperado e oferecido à criança. Esse levantamento deve ser feito cuidadosa e sistematicamente, ao longo de vários atendimentos. Não é adequado fazer entrevistas longas e preencher questionários intermináveis no primeiro contato que se tem 
com a criança e sua família. É vital compreender o que a doença na infância significa para a família, para tanto, devese considerar a estrutura e as funções de cada família específica. Ampliar essa etapa, através de contatos com pessoas ou instituições voluntárias que dão apoio à família, pode ser útil, pois, às vezes, a família tem mais facilidade em compartilhar seus dilemas em redes de apoio.

- Diagnóstico de enfermagem

O diagnóstico de enfermagem é o julgamento das habilidades dos pais e demais membros da família para enfrentamento de demandas emocionais e operacionais no acompanhamento do crescimento e desenvolvimento da criança ${ }^{(10)}$.

- Planejamento de enfermagem

Nesta etapa, deve-se incluir, no processo, todos os membros da família ou sua maioria. O plano deve também considerar a comunidade como um lugar em que possam compartilhar experiências (com vizinhos e amigos). Além disso, deve-se encorajar os membros a se comunicarem e tomarem decisões compartilhadas.

- Implementação

A implementação é, de fato, a prestação de cuidados de enfermagem. Um plano, para promover e melhorar a saúde da família pode ser implementado mais facilmente se os membros estiverem de acordo em se ajudarem uns aos outros. Às vezes, pode ser necessário encorajar os membros a terem um objetivo comum.

- Avaliação dos resultados

Na avaliação, pretende-se verificar se os objetivos foram atingidos conforme propostos na metodologia de assistência. Contudo, isso não é suficiente, pois é importante verificar, também, o quanto a família sente-se mais unida trabalhando em conjunto. Se a avaliação revela que esses dois fatores não foram atingidos, é necessário novo levantamento de dados e novos planos de intervenção.

\section{INSTRUMENTOS PARA ASSISTÊNCIA À CRIANÇA EM UMA ABORDAGEM DE ENFERMAGEM DA FAMÍLIA}

Há diferentes modalidades de cuidados que utilizam a observação e o histórico como instrumentos para coleta de dados. Quanto mais detalhada essa coleta de informações, mais eficiente será a avaliação preliminar para o diagnóstico. Para o histórico, sugerem-se os seguintes itens: tipo de família, recursos financeiros, segurança, saúde, suporte emocional interno e externo, papéis familiares, cuidadores e provedores da criança, quem toma as decisões, quem resolve os problemas, quem gerencia as questões de saúde e quem controla as informações.

A seguir apresentamos os instrumentos sugeridos por Pillitteri ${ }^{(8)}$.

APGAR da família

O APGAR da família é um instrumento de avaliação destinado a refletir a satisfação de cada membro, e os diferentes escores devem ser comparados para se avaliar o estado funcional da família. O acrônimo APGAR proveniente da língua Inglesa, é deAdaptação (Adaptation), Participação (Partneship), Crescimento (Growth), Afeição (Affection) e Resolução (Resolve).

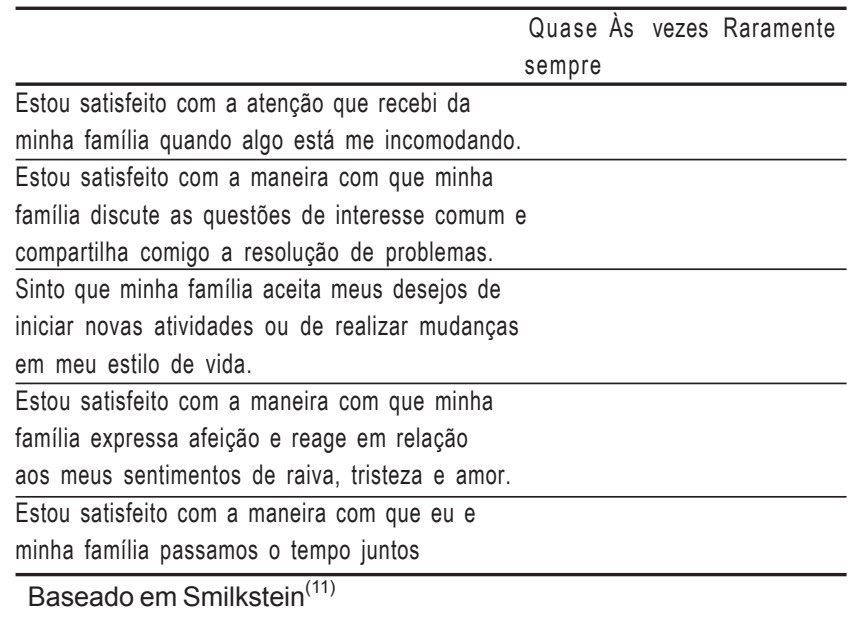

Figura 1 - Questionário APGAR familiar

- Pontuação: O paciente assinala uma das três escolhas, as quais têm a seguinte pontuação: 2 pontos para "Quase sempre", 1 ponto para "Às vezes", e 0 para "Raramente". Os pontos para cada uma das cinco questões são totalizados. O resultado de 7 a 10 sugere uma família altamente funcional. $O$ resultado de 4 a 6 sugere uma família moderadamente disfuncional. $\mathrm{O}$ resultado de 0 a 3 sugere uma família severamente disfuncional.

- O que é medido

- Adaptação: Como os recursos são compartilhados ou qual o grau de satisfação do membro familiar com a atenção recebida, quando recursos familiares são necessários.

- Participação: Como as decisões são compartilhadas ou qual a satisfação do membro da família com a reciprocidade da comunicação familiar e na resolução de problemas.

- Crescimento: Como a promoção do crescimento é 
compartilhada ou qual a satisfação do membro da família com a liberdade disponível no ambiente familiar, para a mudança de papéis e para a concretização do crescimento emocional ou amadurecimento.

- Afeição: Como as experiências emocionais são compartilhadas ou qual a satisfação do membro da família com a intimidade e interação emocional no contexto familiar.

- Resolução: Como o tempo é compartilhado ou qual a satisfação do membro familiar com o compromisso que tem sido estabelecido pelos seus próprios membros. Além de repartirem seu tempo, familiares geralmente estabelecem um compromisso no compartilhamento de espaço e dinheiro.

\section{Genograma}

O genograma é um diagrama que detalha a estrutura e o histórico familiar, fornece informações sobre os vários papéis de seus membros e das diferentes gerações. Os homens são representados por quadrados e as mulheres por círculos e cada membro é identificado pelo nome, idade e ocupação. O genograma fornece bases para a discussão e análise das interações familiares.

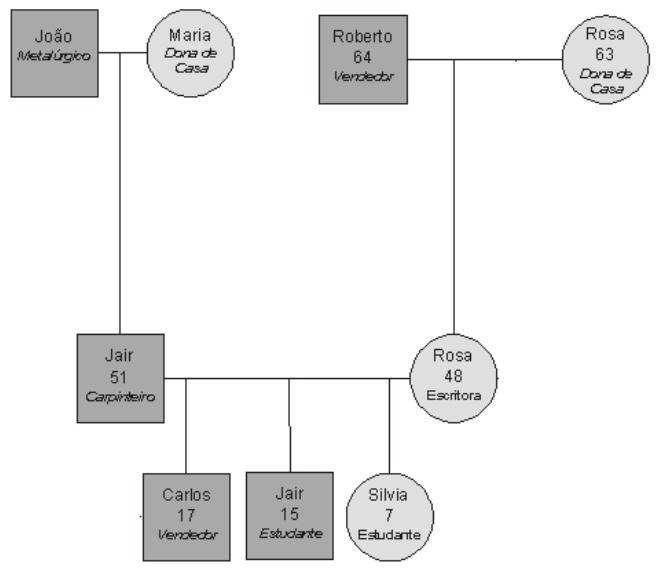

Baseado em Friedman ${ }^{(12)}$

Figura 2 - Genograma

Para exemplificar, trazemos o estudo de Sílvia e sua família. Sílvia é uma criança com doença crônica, sexo feminino, com 7 anos de idade e estudante. Seus pais, Jair e Rosa, com 51 e 48 anos respectivamente, possuem outros dois filhos. Carlos com 17 e Jair com 15 anos. Os avós paternos já faleceram, e os avós maternos sobreviventes moram distante e têm pouco contato com a família.

Para situar essa família em suas relações na comunidade à qual pertence, há vários instrumentos descritos na literatura. Destacamos o ecomapa, apresentado a seguir.

\section{Ecomapa}

O ecomapa é um diagrama das relações entre a família e a comunidade e ajuda a avaliar os apoios e suportes disponíveis e sua utilização pela família. Uma família que tem poucas conexões com a comunidade e entre seus membros necessita maior investimento da enfermagem para melhorar seu bem estar. Os membros da família e suas idades são mostrados no centro do círculo. Os círculos externos mostram os contatos da família com a comunidade. As linhas indicam o tipo de conexão: linhas contínuas representam ligações fortes; linhas pontilhadas, ligações frágeis; linhas com barras, aspectos estressantes. As setas significam energia e fluxo de recursos. Ausência de linhas significa ausência de conexão. Pode-se usar de forma combinada o genograma com o ecomapa.

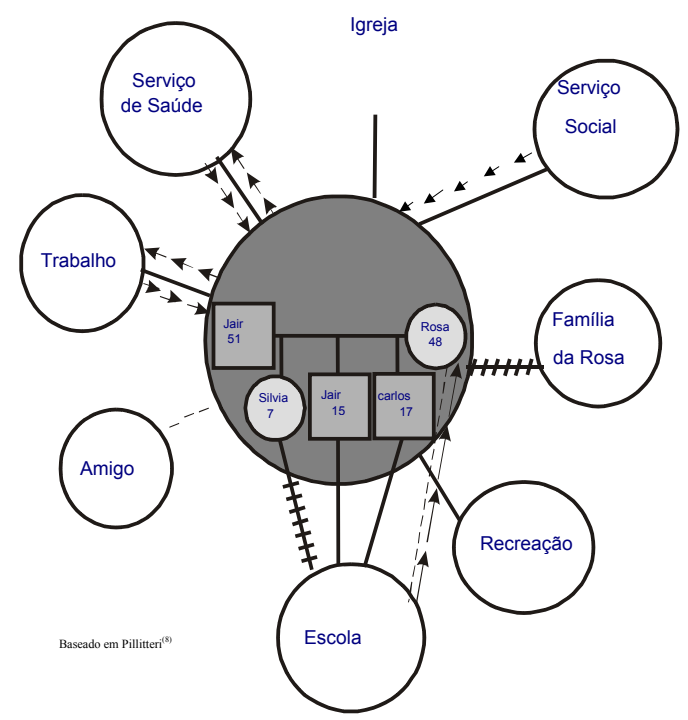

Figura 3 - Ecomapa

O ecomapa da família da Sílvia demonstra o forte fluxo de energia e recursos com o serviço de saúde e trabalho. As setas nos dois sentidos significam que este fluxo é recíproco, os serviços de saúde estão direcionados para a família assim como a família está direcionada para os serviços. Essa relação ocorre também com o trabalho.

O gráfico demonstra que a relação do Serviço Social com a família é intensa, contudo a família não demonstra reciprocidade. As barras, na linha que liga o genograma à família de origem de Rosa, indicam que as relações entre as duas famílias são estressantes. 
As mesmas barras estão presentes na ligação entre Sílvia e a escola, significando, também, relações estressantes. As relações de Rosa, mãe de Sílvia, com a escola do seus filhos é frágil, embora o gráfico demonstre que a escola procura intensificar o fluxo de relação com ela. Os dois outros filhos mantêm relações adequadas com a escola. Há demonstração de uma relação frágil da família com seus amigos e relação adequada com a igreja e atividades de recreação.

A partir desses levantamentos, passa-se aos demais passos da metodologia de assistência: identificação dos problemas, diagnóstico, discussão das estratégias de intervenção e objetivos a serem atingidos, implementação e avaliação de resultados.

Assim, no caso, o cuidado à criança com doença crônica passa a ser dimensionado na família e comunidade e não somente circunscrito aos recursos do setor saúde.

\section{CONSIDERAÇÕES GERAIS}

Conforme nos propusemos, buscamos, na literatura internacional atual, instrumentos que ainda são

\section{REFERÊNCIAS BIBLIOGRÁFICAS}

1. Ministério da Saúde (BR). Secretaria da Assistência à Saúde. Coordenação da Saúde da Comunidade, Saúde da Família: uma estratégia para a reorientação do modelo assistencial. Brasília; 1998

2. Constituição da República Federativa do Brasil. Capítulo

2, seção 1 e 2, artigos 94-200. Brasília;1988.

3. Friedman ML. The concept of family nursing Adv Nurs 1989;

14:211-6.

4. Whall AL. Nursing theory and the assessment of families. Psychiatr Nurs Mental Health Services, 1981; 19:30-6.

5. Demo DH, Cox JM. Familes with young children: a review of research in the 1990s. In: Milardo RM, editors. Understanding families into the new millennium: a decade in review. Minneapolis, MN: National Council of Family Relations; 2001. p.95-114.

6. Hayes VE. Familes and children's chronic conditions: knowledge development and methodological considerations. Scholarly Inquiry Nurs Practice 1997;11:259-90.

7. Yeh $\mathrm{CH}$, Lin CF, Tsai JL, Lai YM, Ku HC Determinants of parental decisions on 'drop out' from cancer treatment for childhood cancer patients. Adv Nurs 1999; 30:193-9.

8. Pillitteri A. Child health nursing: care of the child and family. Philadelphia: Lippincott; 1999.

9. Kendall D, Linden R, Murray JC. Sociology our times: the essential. Toronto: ITP Nelson; 1998. pouco utilizados pela enfermagem brasileira na assistência à criança em abordagens de enfermagem da família. Essa busca tem a finalidade de ampliar as perspectivas do ensino de enfermagem pediátrica e neonatal.

É preciso ressaltar que os instrumentos, como o próprio nome indica, são ferramentas para ajudar o enfermeiro a fazer o diagnóstico, dispondo e organizando os dados de forma a serem mais bem visualizados. Eles não substituem uma fundamentação teórica de assistência, nem tampouco a razão e o discernimento do enfermeiro para imprimir sentido e significado aos dados e encontrar as melhores soluções para o cuidado à criança e sua família.

\section{AGRADECIMENTOS}

Agradecemos ao Conselho Nacional de Desenvolvimento Científico e Tecnológico (CNPq) e Fundação de Amparo à Pesquisa do Estado de São Paulo (FAPESP) pelo financiamento deste trabalho através dos processos CNPq 524507/96-1, CNPq 521081/98-0 e FAPESP 00/09992-6.

10. Melnyk BM, Feinstein NF, Moldenhouer Z, Small L. Coping in parents of children who are chronically ill: stragegies for assesment anal intervention. Pediatr Nurs 2001; 27(6):54858.

11. Smillkstein G. The family APGAR: a proposal for a family function test and its use by physicians. J Fam Pract 1978; 6(6):1231-9.

12. Friedman LC. Family nursing. $4^{\text {th }}$ ed. New York: PrenticeHall; 1997. 